\title{
Static Compliance and Driving Pressure are Associated with ICU Mortality in Intubated COVID- 19 ARDS
}

\section{Annalisa Boscolo}

Azienda Ospedale Universita Padova

Nicolò Sella

Universita degli Studi di Padova

Giulia Lorenzoni

Universita degli Studi di Padova

Tommaso Pettenuzzo

Azienda Ospedale Universita Padova

\section{Laura Pasin}

Azienda Ospedale Universita Padova

\section{Chiara Pretto}

Universita degli Studi di Padova

\section{Martina Tocco}

Universita degli Studi di Padova

\section{Enrico Tamburini}

Universita degli Studi di Padova

\section{Alessandro De Cassai}

Azienda Ospedale Universita Padova

\section{Paolo Rosi}

Regione Veneto

\section{Enrico Polati}

Universita degli Studi di Verona

\section{Katia Donadello}

Universita degli Studi di Verona

\section{Leonardo Gottin}

Universita degli Studi di Verona

\section{Silvia De Rosa}

Ospedale San Bortolo di Vicenza

\section{Fabio Baratto}

Azienda ULSS 6 Euganea

\section{Fabio Toffoletto}


ULSS 10 Veneto Orientale: Azienda ULSS 4 Veneto Orientale

\section{Marco Ranieri}

Universita di Bologna

\section{Dario Gregori}

Universita degli Studi di Padova

\section{Paolo Navalesi ( $\sim$ pnavalesi@gmail.com )}

Universita degli Studi di Padova Scuola di Medicina e Chirurgia https://orcid.org/0000-0002-37333453

\section{Research}

Keywords: COVID-19, ARDS, mechanical ventilation, driving pressure, respiratory system compliance.

Posted Date: April 13th, 2021

DOl: https://doi.org/10.21203/rs.3.rs-399976/v1

License: (c) (i) This work is licensed under a Creative Commons Attribution 4.0 International License. Read Full License

Version of Record: A version of this preprint was published at Critical Care on July 28th, 2021. See the published version at https://doi.org/10.1186/s13054-021-03667-6. 


\section{Abstract}

Background: ascertaining whether respiratory system static compliance (Crs), driving pressure (DP), and tidal volume normalized for ideal body weight (VT/kg IBW) at the $1^{\text {st }}$ day of controlled mechanical ventilation (CMV) are associated with intensive care unit (ICU) mortality in COVID-19 acute respiratory distress syndrome (ARDS).

Methods: observational multicenter cohort study. All consecutive COVID-19 adult patients admitted to 25 ICUs belonging to the COVID-19 VENETO ICU network (February $28^{\text {th }}$-April $28^{\text {th }}, 2020$ ), who received CMV, were screened. Only patients fulfilling ARDS criteria and with complete records of Crs, DP and VT/kg IBW within the $1^{\text {st }}$ day of CMV were included. Crs, DP and VT/kg IBW were collected in sedated, paralyzed and supine patients.

Results: 704 COVID-19 patients were screened and 241 enrolled. Seventy-one patients (29\%) died in ICU. The logistic regression analysis showed that: $i$ ) Crs was not linearly associated with ICU mortality (pvalue for non-linearity $=0.01$ ), with a greater risk of death for values $<48 \mathrm{ml} / \mathrm{cm} \mathrm{H}_{2} \mathrm{O}$; ii) the association between DP and ICU mortality was linear ( $p$-value for non-linearity=0.68), and increasing DP from 10 to $14 \mathrm{cmH}_{2} \mathrm{O}$ caused significant higher odds of in-ICU death (OR 1.45, 95\% $\mathrm{Cl} 1.06-1.99$ ); iii) VT/kg IBW was not associated with a significant increase of the risk of death (OR $0.92,95 \% \mathrm{Cl} 0.55-1.52)$. Multivariable analysis confirmed these findings.

Conclusions: $\mathrm{Crs}<48 \mathrm{ml} / \mathrm{cmH}_{2} \mathrm{O}$ was associated with ICU mortality, while DP was linearly associated with mortality. DP should be kept as low as possible, even in the case of relatively preserved Crs, irrespective of $\mathrm{VT} / \mathrm{kg}$ IBW, to reduce the risk of death.

\section{Background}

Pathophysiological features of coronavirus disease 2019 (COVID-19) associated acute respiratory distress syndrome (COVID-19 ARDS) were indicated being somewhat different from those described in nonCOVID-19 ARDS, because of relatively preserved high compliance of the respiratory system despite marked hypoxemia $[1,2]$. These preliminary observations led some authors to question the efficacy of lung protective ventilation in patients with COVID-19 ARDS and suggested that a less tight limitation of volume could be allowed while delivering mechanical ventilation to these patients [2]. Other authors, however, proposed that protective ventilation limiting volume and pressure should be applied also in COVID-19 ARDS [3]. While strong evidence showed that lung protective ventilation improves survival in nonCOVID-19 ARDS patients [4-6], data are still lacking on COVID-19 ARDS patients.

In order to assess whether lung protective ventilation affects intensive care unit (ICU) mortality also in patients with COVID-19 ARDS, we set up a study to test the hypothesis that static compliance of the respiratory system (Crs), driving pressure (DP), and tidal volume normalized for ideal body weight (VT/kg IBW) are associated with ICU mortality. 


\section{Methods}

This multicenter observational study was coordinated by Padua University Hospital (Italy), and followed the "Strengthening the Reporting of Observational Studies in Epidemiology" statement guidelines for observational cohort studies (Additional File 1) [7]. The study was approved by the Institutional Ethical Committee of each participating centre (coordinator centre approval reference number 4853AO20, while the full list of all approval reference numbers is available in Additional File 2) and informed consent was obtained according to the national regulation. Data were collected by the COVID-19 VENETO ICU Network, including 25 ICUs [8], and inserted into a pre-designed online data acquisition system (www.covid19veneto.it). Patients' privacy was protected by assigning a de-identified patient code.

We included all consecutive adult patients with confirmed SARS-CoV-2 infection and fulfilling ARDS criteria [1], admitted between February 28th and April 28th, 2020, who received controlled mechanical ventilation (CMV) and had Crs, DP and VT/ kg IBW measured in supine position, after sedation and paralysis, within the first 24 hours of CMV. We excluded the patients with incomplete records, and those who had been prone positioned prior to data collection. COVID-19 diagnosis was made according to the WHO interim guidance (http://www.who.int/docs/default-source/coronaviruse/clinical-management-ofnovel-cov.pdf).

The following variables were collected: i) demographic data (age, gender, body mass index); ii) Charlson Comorbidity Index not adjusted for age; iii) sequential organ failure assessment (SOFA) score at ICU admission; iv) gas exchange within the first 24 hours of $\mathrm{CMV}[\mathrm{pH}$, arterial partial pressure of oxygen $\left(\mathrm{PaO}_{2}\right)$, arterial partial pressure of carbon dioxide $\left(\mathrm{PaCO}_{2}\right)$ ]; $v$ ) ventilator settings [VT/kg IBW, respiratory rate, positive end-expiratory pressure (PEEP), fraction of inspired oxygen $\left(\mathrm{FiO}_{2}\right)$ ]; vi) plateau pressure, $\mathrm{DP}$, Crs; vii) ICU mortality.

Ventilator settings, plateau pressure, DP and Crs were collected within the first 24 hours after endotracheal intubation in supine position on the basis of the senior attending physician's assessment. The measurements were performed in sedated and paralyzed patients, with no spontaneous breathing activity. Patients were ventilated in volume-controlled mode. Plateau pressure and total PEEP were measured at zero flow point during end-inspiratory and end-expiratory pauses $[5,6]$. DP was calculated as the difference between plateau pressure and PEEP, while Crs was calculated as VT/DP $[5,6]$.

Prior to data analysis, two independent investigators and a statistician screened the database for errors against standardized ranges and contacted local investigators for any queries. Validated data were then entered into the final database. Patients transferred from one ICU to another were considered as a single case, while for those readmitted to ICU after discharge, only data from the first admission were considered.

\section{Statistical analysis.}


Categorical data are presented as absolute numbers (n) and percentages (\%). For continuous data, normality was tested by Skewness and Kurtosis tests. Means and standard deviations are used for normally distributed variables, while medians and interquartile ranges are used for non-normally distributed variables. No imputation for missing data has been planned. Logistic regression models have been estimated to assess the association between ICU mortality and Crs, DP and VT/kg IBW. If the association was nonlinear, restricted cubic splines have been used to estimate the models and the change-point has been identified.

Additionally, multivariable logistic regression models have been used to evaluate the association between Crs and DP and ICU mortality after adjusting for relevant confounders. In each model, the independent predictors have been identified through a stepwise regression approach. This approach combines forward and backward selection methods in an iterative procedure (with a significance level of 0.05 both for entry and retention) to select predictors in the final multivariable model [9]. Independent variables used in the stepwise approach were age, gender, body mass index, SOFA score at ICU admission, Charlson comorbidity index, $\mathrm{pH}, \mathrm{PaO}_{2} / \mathrm{FiO}_{2}, \mathrm{PaCO}_{2}$, ventilator settings $(\mathrm{VT} / \mathrm{kg}$ IBW, respiratory rate, PEEP, $\mathrm{FiO}_{2}$ ) and plateau pressure at the first day of CMV. Additionally, collinearity has been defined for $\operatorname{GVIF}(1 /(2 \times D f))$ value greater than 2 [10]. Variables with multicollinearity have been removed from the model. Two different multivariable logistic regression models, one for $\mathrm{Crs}$ (model 1 ) and one for DP (model 2), were generated.

All statistical tests were 2-tailed, and statistical significance was defined as $p<0.05$. All analyses have been conducted using R version 4.0.3 ( $R$ foundation for Statistical Computing, Vienna, Austria).

\section{Results}

During the study period, a total of 704 consecutive COVID-19 ARDS patients from 25 ICUs were included in the database. After excluding 463 patients, who did not receive CMV or did not fulfill ARDS criteria [1] or did not have complete records in supine position, 241 patients from 21 ICUs were deemed eligible for data analysis (Fig. 1).

Demographic and clinical characteristics of the study population are listed in Table 1. 
Table 1

Clinical characteristics, respiratory parameters and outcomes of the study population.

Overall population

$n=241$

Clinical characteristics

Age (years)

66 [58-73]

Gender (male)

$189(78 \%)$

SOFA score at ICU admission

$5[4-8]$

$B M I\left(k g / m^{2}\right)$

$27[25-30]$

Charlson comorbidity index

$1[1-2]$

Onset of symptoms (days)

$7[3-9]$

Hospital LOS before ICU (days)

$2[1-5]$

Hospital LOS before CMV (days)

$2[1-5]$

Gas exchange, at first day of CMV

$\mathrm{pH}$

$7.41[7.36-7.46]$

$\mathrm{PaO}_{2} / \mathrm{FiO}_{2}(\mathrm{mmHg})$

$142[102-216]$

$\mathrm{PaCO}_{2}(\mathrm{mmHg})$

$44[38-52]$

Ventilator settings and variables, at first day of CMV

Tidal volume ( $\mathrm{ml} / \mathrm{kg}$ of ideal body weight)

$7.8[6.9-8.8]$

Set respiratory rates (breaths/min)

$16[14-20]$

$\operatorname{PEEP}\left(\mathrm{CmH}_{2} \mathrm{O}\right)$

$12[10-13]$

$\mathrm{FiO}_{2}(\%)$

$60[50-70]$

Plateau pressure $\left(\mathrm{CmH}_{2} \mathrm{O}\right)$

$23[20-26]$

Driving pressure $\left(\mathrm{CmH}_{2} \mathrm{O}\right)$

$11[9-13]$

Data are expressed as median and interquartile range [IQR] or number (\%).

Abbreviations: SOFA: sequential organ failure assessment; ICU: intensive care unit; BMI: body mass index; LOS: length of stay; CMV: controlled mechanical ventilation; $\mathrm{PaO}_{2}$ : partial pressure of arterial oxygen; $\mathrm{PaO}_{2} / \mathrm{FiO}_{2}$ : ratio between partial pressure of arterial oxygen and fraction of inspired oxygen; $\mathrm{PaCO}_{2}$ : partial pressure of carbon dioxide; PEEP: positive end-expiratory pressure; $\mathrm{FiO}_{2}$ : fraction of inspired oxygen; NIV: non-invasive ventilation; HFOT: high flow oxygen therapy; V-V: veno-venous; V-A: veno-arterial; ECMO: extracorporeal membrane oxygenation. 


\begin{tabular}{|c|c|}
\hline & $\begin{array}{l}\text { Overall population } \\
\mathrm{n}=241\end{array}$ \\
\hline Static compliance of the respiratory system $\left(\mathrm{ml} / \mathrm{cmH}_{2} \mathrm{O}\right)$ & $48[39-60]$ \\
\hline \multicolumn{2}{|l|}{ Respiratory treatments before $\mathrm{CMV}$} \\
\hline NIV failure & $110(46 \%)$ \\
\hline HFOT failure & $27(11 \%)$ \\
\hline None & $104(43 \%)$ \\
\hline \multicolumn{2}{|l|}{ Adjunctive therapies during ICU stay } \\
\hline Prone position & $202(84 \%)$ \\
\hline Neuromuscular blockers $>24$ hours & $212(88 \%)$ \\
\hline$V$-V ECMO & $5(2 \%)$ \\
\hline$V-A$ ECMO & $1(0.4 \%)$ \\
\hline \multicolumn{2}{|l|}{ Outcomes } \\
\hline ICU mortality & $71(29 \%)$ \\
\hline 60-day mortality & $78(32 \%)$ \\
\hline Length of CMV (days) & $12[7-16]$ \\
\hline ICU LOS (days) & $15[9-25]$ \\
\hline Hospital LOS (days) & $30[18-41]$ \\
\hline \multicolumn{2}{|c|}{ Data are expressed as median and interquartile range [IQR] or number (\%). } \\
\hline \multicolumn{2}{|c|}{ 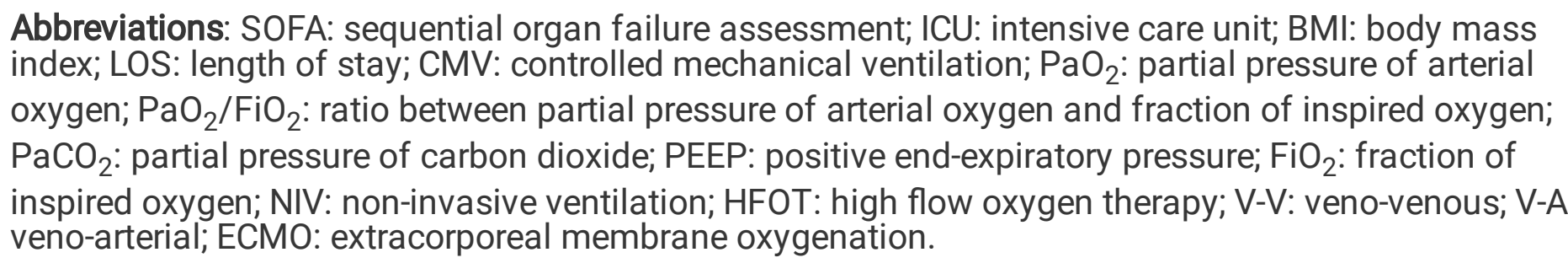 } \\
\hline
\end{tabular}

On the first day of CMV, median Crs was 48 [39-60] $\mathrm{ml} / \mathrm{cmH}_{2} \mathrm{O}$, DP 11 [9-13] $\mathrm{cmH}_{2} \mathrm{O}$ and VT/kg IBW 7.8 [6.9-8.8] ml/kg. Seventy-one patients (29\%) died in ICU.

The logistic regression analysis revealed a nonlinear relationship between Crs and ICU mortality ( $\mathrm{p}$-value for non-linearity $=0.01$ ), with a significantly greater risk of death for values below $48 \mathrm{ml} / \mathrm{cmH}_{2} \mathrm{O}(\mathrm{Fig} .2 \mathrm{~A})$.

Contrariwise, a linear relationship between DP and ICU mortality ( $p$-value for non-linearity $=0.68$ ) was observed. An increase of DP from 10 to $14 \mathrm{cmH}_{2} \mathrm{O}$ was associated with a $45 \%$ increment of the risk of 
ICU mortality (OR 1.45, 95\% Cl 1.06-1.99) (Fig. 2B).

VT/ $\mathrm{kg}$ IBW was not associated with ICU mortality. Increasing VT $/ \mathrm{kg} \mathrm{IBW} \mathrm{from} 6 \mathrm{ml} / \mathrm{kg}$ to $8 \mathrm{ml} / \mathrm{kg}$ or from $8 \mathrm{ml} / \mathrm{kg}$ to $10 \mathrm{ml} / \mathrm{kg}$ did not increase the risk of death (OR 0.92, 95\% Cl 0.55-1.52, for both ranges)

(Fig. 2C).

Multivariable analysis confirmed Crs and DP to be independent risk factors for ICU mortality (OR 0.98 , 95\% $\mathrm{Cl} 0.96-1.00, \mathrm{p}=0.03$ and OR 1.12, 95\% $\mathrm{Cl} 1.00-1.24, \mathrm{p}=0.04$, respectively) (Table 2).

Table 2

Multivariable models on the association between ICU mortality and static compliance of respiratory system (model 1 ) and driving pressure (model 2 ) at the first day of invasive controlled mechanical ventilation.

\begin{tabular}{|c|c|c|}
\hline \multicolumn{3}{|c|}{ MODEL 1} \\
\hline & OR $(95 \% \mathrm{Cl})$ & p-value* \\
\hline Age (years) & $1.10[1.05-1.15]$ & $<0.01$ \\
\hline \multirow{3}{*}{$\begin{array}{l}\text { Static compliance of the respiratory system } \\
\text { (per } \mathrm{ml} / \mathrm{cmH}_{2} \mathrm{O} \text { increase) }\end{array}$} & $0.98[0.96-1.00]$ & 0.03 \\
\hline & \multicolumn{2}{|l|}{ MODEL 2} \\
\hline & OR $(95 \% \mathrm{Cl})$ & $p$-value* \\
\hline Age (years) & $1.10(1.05-1.15)$ & $<0.01$ \\
\hline Driving pressure (per $\mathrm{CmH}_{2} \mathrm{O}$ increase) & $1.12(1.00-1.24)$ & 0.04 \\
\hline \multicolumn{3}{|c|}{ Data are expressed as Odds ratio (OR) and 95\% Confidence Interval (CI). } \\
\hline \multicolumn{3}{|c|}{$\begin{array}{l}\text { *: Stepwise regression approach, combining forward and backward selection methods (with a } \\
\text { significance level of } 0.05 \text { both for entry and retention), was applied to select predictors in the final } \\
\text { multivariable model. Independent variables used in the stepwise approach were age, gender, body } \\
\text { mass index, SOFA score at ICU admission, Charlson comorbidity index, } \mathrm{PaO}_{2} / \mathrm{FiO}_{2}, \mathrm{PaCO}_{2}, \mathrm{VT} / \mathrm{kg} \mathrm{IBW,} \text {, } \\
\text { respiratory rate, } \mathrm{PEEP}, \mathrm{FiO}_{2} \text {; while ph and plateau pressure were excluded from the model due to } \\
\text { collinearity. }\end{array}$} \\
\hline \multicolumn{3}{|c|}{$\begin{array}{l}\text { Abbreviations: ICU, intensive care unit; HFOT, high flow oxygen therapy; NIV, non-invasive ventilation; } \\
\text { CMV: controlled mechanical ventilation; ARDS: acute respiratory distress syndrome; DP, driving } \\
\text { pressure; Crs, static compliance of the respiratory system. }\end{array}$} \\
\hline
\end{tabular}

\section{Discussion}

We found that in COVID-19 ARDS patients $i$ ) Crs has a nonlinear relationship with ICU mortality, with a greater risk of death for values below $48 \mathrm{ml} / \mathrm{cmH}_{2} \mathrm{O}$; ii) DP is associated with ICU mortality, which increases linearly with DP increment; iii) VT/kg IBW is not a significant risk factor of ICU mortality. 
In nonCOVID-19 ARDS patients, Crs failed to predict clinical outcomes, despite being associated with the functional lung size and the severity of the syndrome $[5,11]$. A secondary analysis of the LUNG SAFE study, however, showed that lower Crs values, recorded on the first day of ARDS, were independently associated with mortality, even though the Crs-mortality relationship lacked a clear transition point and no useful cutoff could be established [9].

Wide ranges of Crs have been reported in COVID-19 ARDS patients $[2,12,13]$, but the relationship between $\mathrm{Crs}$ and mortality remains uncertain $[14,15]$. Grasselli et al. found that, among patients with COVID-19 ARDS, those who presented 'low' Crs within 24 hours from ICU admission, associated with 'high' D-dimer concentration, had significantly greater 28-day mortality [14]. However, other studies were not able to confirm these results $[13,15]$.

We found Crs to be nonlinearly correlated with ICU mortality, with a significant association only for Crs values below $48 \mathrm{ml} / \mathrm{cmH}_{2} \mathrm{O}$. This nonlinear relationship, which has already been reported in nonCOVID-19 ARDS patients [9], may depend on clinically relevant phenotypic heterogeneity $[2,3,16,17]$, and could explain the inconsistent results of previous investigations testing the association between Crs and mortality using a linear statistical approach [13-15].

DP has been extensively studied in nonCOVID-19 ARDS patients and was associated with poor clinical outcomes [5, 6]. Indeed, in a post-hoc observational study including 3562 ARDS patients, DP proved to be the variable that best stratified 60-day mortality risk, irrespective of PEEP, plateau pressure and VT/kg IBW [5]. Furthermore, the LUNG SAFE study, which enrolled 2377 intubated ARDS patients, showed that DP > $14 \mathrm{cmH}_{2} \mathrm{O}$ on the first day of $\mathrm{CMV}$ is a risk factor of poor hospital survival [6]. For patients without ARDS, the effect of DP on the clinical outcome is still controversial [18-20], though a meta-analysis including 2250 patients found that high DP during general anesthesia was associated with more postoperative pulmonary complications [21]. In COVID-19 ARDS patients, some cohort studies reported DP values quite close to those of nonCOVID-19 ARDS patients $[12,22]$, though the predictive role of DP on mortality remains unclear [13].

To the best of our knowledge, the present study is the first investigation finding a significant association between DP and mortality in COVID-19 ARDS patients receiving CMV. This linear relationship suggests that every effort should be made to reduce DP as much as possible. If, on the one hand, this is quite easy to accomplish when Crs is relatively preserved, on the other hand, when $\mathrm{Crs}$ is low, extracorporeal $\mathrm{CO}_{2}$ removal may be necessary to achieve this goal. Interestingly, the effect of DP on ICU mortality seems to be independent from VT/kg IBW, whose increment above the traditional cutoff value [4] did not affect patient outcome. Similar results have been recently reported in nonCOVID-19 ARDS patients by a post-hoc secondary analysis of 5 randomized trials, including 1096 classical ARDS patients, which found that the benefit of lower tidal volumes (4-8 $\mathrm{ml} / \mathrm{kg} \mathrm{IBW}$ ) on 60-day mortality was related to respiratory system elastance, suggesting that lung-protective ventilation strategies should primarily target driving pressure rather than tidal volume [23]. 
Our study has limitations. First, like the vast majority of the studies published during COVID-19 pandemia, it is an observational study, suffering the limits of this design. Second, we measured Crs and DP, which include the mechanical properties of the chest wall, in addition to those of the lung. Worth mentioning, however, a recent meta-analysis showed that more sophisticated respiratory parameters did not add important information on the risk of death in comparison to DP [24]. Third, our findings focus only on respiratory variables collected within the first day of $\mathrm{CMV}$, while subsequent measurements during ICU stay were not considered. Although this approach has already been used by several published papers [6, $9,14]$, it fails exploring the role of further clinical evolution after the first day. Moreover, the lead-time bias in the form of time period for which patients fulfilled ARDS criteria [1] or had ARDS before the assessment on the first day of CMV remains an unmeasured confounder [9]. Lastly, several patients were excluded for incomplete records, which depended on the overwhelming workload for ICU physicians during the COVID-19 pandemic making data recording problematic, especially in hospitals not included in the residency program.

\section{Conclusions}

In COVID-19 ARDS patients receiving CMV, ICU mortality is associated with Crs $<48 \mathrm{ml} / \mathrm{cmH}_{2} \mathrm{O}$ and linearly associated with DP. Our results suggest that DP should be kept as low as possible, irrespective of $\mathrm{VT} / \mathrm{kg}$ IBW, to reduce the risk of death.

\section{Abbreviations}

- COVID-19, coronavirus disease 2019

- ARDS, acute respiratory distress syndrome

- ICU, intensive care unit

- Crs, static compliance of the respiratory system

- DP, driving pressure

- VT/kg IBW, tidal volume normalized for ideal body weight

- CMV, controlled mechanical ventilation

- SOFA, sequential organ failure assessment score

- $\mathrm{PaO}_{2}$, arterial partial pressure of oxygen

- $\mathrm{PaCO}_{2}$, arterial partial pressure of carbon dioxide

- PEEP, positive end-expiratory pressure

- $\mathrm{FiO}_{2}$, fraction of inspired oxygen

\section{Declarations}


- Ethics approval and consent to participate. The study was approved by the Institutional Ethical Committee of each participating centre (coordinator centre approval reference number 4853AO20, while the full list of all approval reference numbers is available in Additional File 2).

- Consent for publication. Written informed consent was obtained from each patient according to national regulation.

- Availability of data and materials. The data that support the findings of this study are available from the corresponding author, $\mathrm{PN}$, upon request.

- Competing interests. None related to the present work. PN received royalties from Intersurgical for Helmet Next invention and speaking fees from Philips, Resmed, MSD, Drager and Novartis. The other authors have no other competing interests to declare.

- This study was funded by a grant provided by the Regional Government, Veneto, Italy. The regional database was commissioned to the Contract Research Organization Aleph srl (Milan, Italy).

- Authors' contributions. Concept and design: PN, AB, NS, DG. Acquisition, analysis, or interpretation of data: $A B, N S, G L, S D R, F B, F T, D G, P N$. Drafting of the manuscript: AB, NS, GL, TP, LP, ADC. Critical revision of the manuscript for important intellectual content: $P N, P R, E P, K D, L G, V M R$.

\section{ACKNOWLEDGEMENTS}

We are indebted with all ICU personnel who made this work possible.

Members of COVID-19 VENETO ICU Network, that we would like to be searchable through their individual PubMed records, are listed below:

i)O.C. Istituto di Anestesia e Rianimazione, Padova (Ilaria Valeri, MD; Giulio Andreatta, MD; Leonardo Gandolfi, MD; Alessandra Gadaldi, MD; Nicolò Brumana, MD; Edoardo Forin, MD; Christelle Correale, MD; Davide Fregolent, MD; Pier Francesco Pirelli, MD; Davide Marchesin, MD; Matteo Perona, MD; Nicola Franchetti, MD; Michele Della Paolera, MD; Caterina Simoni, MD; Tatiana Falcioni, MD; Alessandra Tresin, MD; Chiara Schiavolin, MD; Aldo Schiavi, MD; Sonila Vathi, MD; Daria Sartori, MD; Alice Sorgato, MD; Elisa Pistollato, MD; Federico Linassi, MD); ii) Azienda Ospedale-Università di Padova, Padova (PD) (Eugenio Serra, MD; Demetrio Pittarello, MD; Ivo Tiberio, MD; Ottavia Bond, MD; Elisa Michieletto, MD; Luisa Muraro, MD; Arianna Peralta, MD; Paolo Persona, MD; Enrico Petranzan, MD; Francesco Zarantonello, MD; Alessandro Graziano, MD; Eleonora Piasentini, MD); iii) U.O.C. Anestesia e Rianimazione, Presidio Ospedaliero San Martino, Belluno (BL), AULSS 1 Dolomiti (Lorenzo Bernardi, MD; Roberto Pianon, MD); iv) U.O.C. Anestesia e Rianimazione, Ospedale di Vittorio Veneto, Vittorio Veneto (TV), AULSS 2 Marca Trevigiana (Flavio Badii, MD); v) U.O.C. Anestesia e Rianimazione, Ospedale di Conegliano, Conegliano (TV), AULSS 2 Marca Trevigiana (Enrico Bosco, MD); vi) U.O.C. Anestesia e Rianimazione, Ospedale di Montebelluna, Montebelluna (TV), AULSS 2 Marca Trevigiana (Moreno Agostini, MD); vii) U.O.C.

Anestesia e Rianimazione, Ospedale Ca' Foncello, Treviso, AULSS 2 Marca Trevigiana (Antonio Farnia, MD; Mario Peta, MD); viii) U.O.C. Anestesia, Rianimazione e Terapia Antalgica, Presidio Ospedaliero di Mirano, Mirano (VE) AULSS 3 Serenissima (Mauro Antonio Calò, MD); ix) U.O.C. Anestesia e 
Rianimazione, Ospedale SS. Giovanni e Paolo, Venezia, AULSS 3 Serenissima (Marco Meggiolaro, MD); x) U.O.C. Anestesia e Rianimazione, Ospedale dell'Angelo, Mestre (VE), AULSS 3 Serenissima (Francesco Lazzari, MD; Ivan Martinello, MD; Giorgio Fullin, MD; Francesco Papaccio, MD); xi) U.O.C. Anestesia e Rianimazione, Ospedale di Cittadella, Cittadella (PD), AULSS 6 Euganea (Alfeo Bonato, MD; Camilla Sgarabotto, MD); xii) U.O.C. Anestesia e Rianimazione, Ospedali Riuniti Padova Sud, Monselice (PD), AULSS 6 Euganea (Francesco Montacciani, MD; Parnigotto Alessandra, MD); xiii) U.O.C. Anestesia e Rianimazione, Ospedali di Rovigo e Trecenta, Rovigo, AULSS 5 Polesana (Giuseppe Gagliardi, MD; Gioconda Ferraro, MD); xiv) U.O.C. Anestesia e Rianimazione, Ospedale Alto Vicentino, Santorso (VI), AULSS 7 Pedemontana (Luigi Ongaro, MD); xv) U.O.C. Anestesia e Rianimazione, Ospedale San Bassiano, Bassano del Grappa (VI), AULSS 7 Pedemontana (Marco Baiocchi, MD); xvi) U.O.C Anestesia e Rianimazione, Ospedale di Vicenza, Vicenza (VI), AULSS 8 Berica (Vinicio Danzi, MD); xvii) U.O.C. Anestesia e Rianimazione A, Azienda Ospedaliera Universitaria Integrata Verona, Verona (VR) (Paolo Zanatta, MD); xviii) U.O.C Anestesia e Rianimazione, Ospedale Magalini di Villafranca, Legnago (VR), AULSS 9 Scaligera (Simonetta Marchiotto, MD; Silvia Bassanini, MD); xix) Dipartimento di Anestesia, Rianimazione e Terapia Antalgica, IRCCS Sacro Cuore-Don Calabria, Negrar (VR) (Massimo Zamperini, MD; Ivan Daroui, MD).

\section{References}

1. ARDS Definition Task Force. Ranieri VM, Rubenfeld GD, Thompson BT, Ferguson ND, Caldwell E, Fan E, et al. Acute respiratory distress syndrome: the Berlin Definition. JAMA 2012; 307(23):2526-33.

2. Gattinoni L, Chiumello D, Caironi P, Busana M, Romitti F, Brazzi L, et al. COVID-19 pneumonia: different respiratory treatments for different phenotypes? Intensive Care Med. 2020;46(6):1099-102.

3. Fan E, Beitler JR, Brochard L, Calfee CS, Ferguson ND, Slutsky AS, et al. COVID-19-associated acute respiratory distress syndrome: is a different approach to management warranted? Lancet Respir Med. 2020;8(8):816-21.

4. Acute Respiratory Distress Syndrome Network. Brower RG, Matthay MA, Morris A, Schoenfeld D, Thompson BT, Wheeler A. Ventilation with lower tidal volumes as compared with traditional tidal volumes for acute lung injury and the acute respiratory distress syndrome. N Engl J Med 2000; 342(18):1301-8.

5. Amato MB, Meade MO, Slutsky AS, Brochard L, Costa EL, Schoenfeld DA, et al. Driving pressure and survival in the acute respiratory distress syndrome. N Engl J Med. 2015;372(8):747-55.

6. Bellani G, Laffey JG, Pham T, Fan E, Brochard L, Esteban A, et al, LUNG SAFE Investigators; ESICM Trials Group. Epidemiology, Patterns of Care, and Mortality for Patients With Acute Respiratory Distress Syndrome in Intensive Care Units in 50 Countries. JAMA. 2016;315(8):788-800.

7. von Elm E, Altman DG, Egger M, Pocock SJ, Gøtzsche PC, Vandenbroucke JP, STROBE Initiative. The Strengthening the Reporting of Observational Studies in Epidemiology (STROBE) statement: guidelines for reporting observational studies. Epidemiology. 2007;18(6):800-4. 
8. Pasin L, Sella N, Correale C, Boscolo A, Rosi P, Saia M, et al. Regional COVID-19 Network for Coordination of SARS-CoV-2 outbreak in Veneto, Italy. J Cardiothorac Vasc Anesth. 2020 Sep;34(9):2341-5.

9. Panwar R, Madotto F, Laffey JG, van Haren FMP. Compliance Phenotypes in Early Acute Respiratory Distress Syndrome before the COVID-19 Pandemic. Am J Respir Crit Care Med. 2020;202(9):124452.

10. Fox J, Monette G. Generalized Collinearity Diagnostics. Am Stat Assoc. 1992;87:178-83.

11. Henderson WR, Chen L, Amato MBP, Brochard LJ. Fifty Years of Research in ARDS. Respiratory Mechanics in Acute Respiratory Distress Syndrome. Am J Respir Crit Care Med. 2017;196(7):822-33.

12. Ferrando C, Suarez-Sipmann F, Mellado-Artigas R, Hernández M, Gea A, Arruti E, et al. COVID-19 Spanish ICU Network. Clinical features, ventilatory management, and outcome of ARDS caused by COVID-19 are similar to other causes of ARDS. Intensive Care Med. 2020;46(12):2200-11.

13. Botta M, Tsonas AM, Pillay J, Boers LS, Algera AG, Bos LDJ, et al, PRoVENT-COVID Collaborative Group. Ventilation management and clinical outcomes in invasively ventilated patients with COVID19 (PRoVENT-COVID): a national, multicentre, observational cohort study. Lancet Respir Med. 2021;9(2):139-48.

14. Grasselli G, Tonetti T, Protti A, Langer T, Girardis M, Bellani G, et al. Pathophysiology of COVID-19associated acute respiratory distress syndrome: a multicentre prospective observational study. Lancet Respir Med. 2020;8(12):1201-8.

15. Vandenbunder B, Ehrmann S, Piagnerelli M, Sauneuf B, Serck N, Soumagne T, et al. COVADIS study group. Static compliance of the respiratory system in COVID-19 related ARDS: an international multicenter study. Crit Care. 2021;25(1):52.

16. Calabrese F, Pezzuto F, Fortarezza F, Boscolo A, Lunardi F, Giraudo C, et al. Machine learning-based analysis of alveolar and vascular injury in SARS-CoV-2 acute respiratory failure. J Pathol 2021. Online ahead of print. Available from doi: 10.1002/path.5653.

17. Gattinoni L, Coppola S, Cressoni M, Busana M, Rossi S, Chiumello D. COVID-19 Does Not Lead to a "Typical" Acute Respiratory Distress Syndrome. Am J Respir Crit Care Med. 2020;201(10):1299-300.

18. Lanspa MJ, Peltan ID, Jacobs JR, Sorensen JS, Carpenter L, Ferraro JP, et al. Driving pressure is not associated with mortality in mechanically ventilated patients without ARDS. Crit Care. 2019;23(1):424.

19. Simonis FD, Barbas CSV, Artigas-Raventós A, Canet J, Determann RM, Anstey J, et al. PRoVENT investigators; PROVE Network investigators. Potentially modifiable respiratory variables contributing to outcome in ICU patients without ARDS: a secondary analysis of PRoVENT. Ann Intensive Care. 2018;8(1):39.

20. Huang $\mathrm{H}, \mathrm{He} \mathrm{H}$. Why driving pressure is not associated with the mortality in non-ARDS patients? Crit Care. 2020;24(1):147.

21. Neto AS, Hemmes SN, Barbas CS, Beiderlinden M, Fernandez-Bustamante A, Futier E, et al. PROVE Network Investigators. Association between driving pressure and development of postoperative 
pulmonary complications in patients undergoing mechanical ventilation for general anaesthesia: a meta-analysis of individual patient data. Lancet Respir Med. 2016;4(4):272-80.

22. Grieco DL, Bongiovanni F, Chen L, Menga LS, Cutuli SL, Pintaudi G, et al. Respiratory physiology of COVID-19-induced respiratory failure compared to ARDS of other etiologies. Crit Care. 2020;24(1):529.

23. Goligher EC, Costa ELV, Yarnell CJ, Brochard LJ, Stewart TE, Tomlinson G, et al. Effect of Lowering Tidal Volume on Mortality in ARDS Varies with Respiratory System Elastance. Am J Respir Crit Care Med 2021. Online ahead of print. Available from doi: $10.1164 / \mathrm{rccm} .202009-35360 \mathrm{C}$.

24. Dianti J, Matelski J, Tisminetzky M, Walkey AJ, Munshi L, Del Sorbo L, et al. Comparing the Effects of Tidal Volume, Driving Pressure, and Mechanical Power on Mortality in Trials of Lung-Protective Mechanical Ventilation. Respir Care. 2021;66(2):221-7.

\section{Figures}

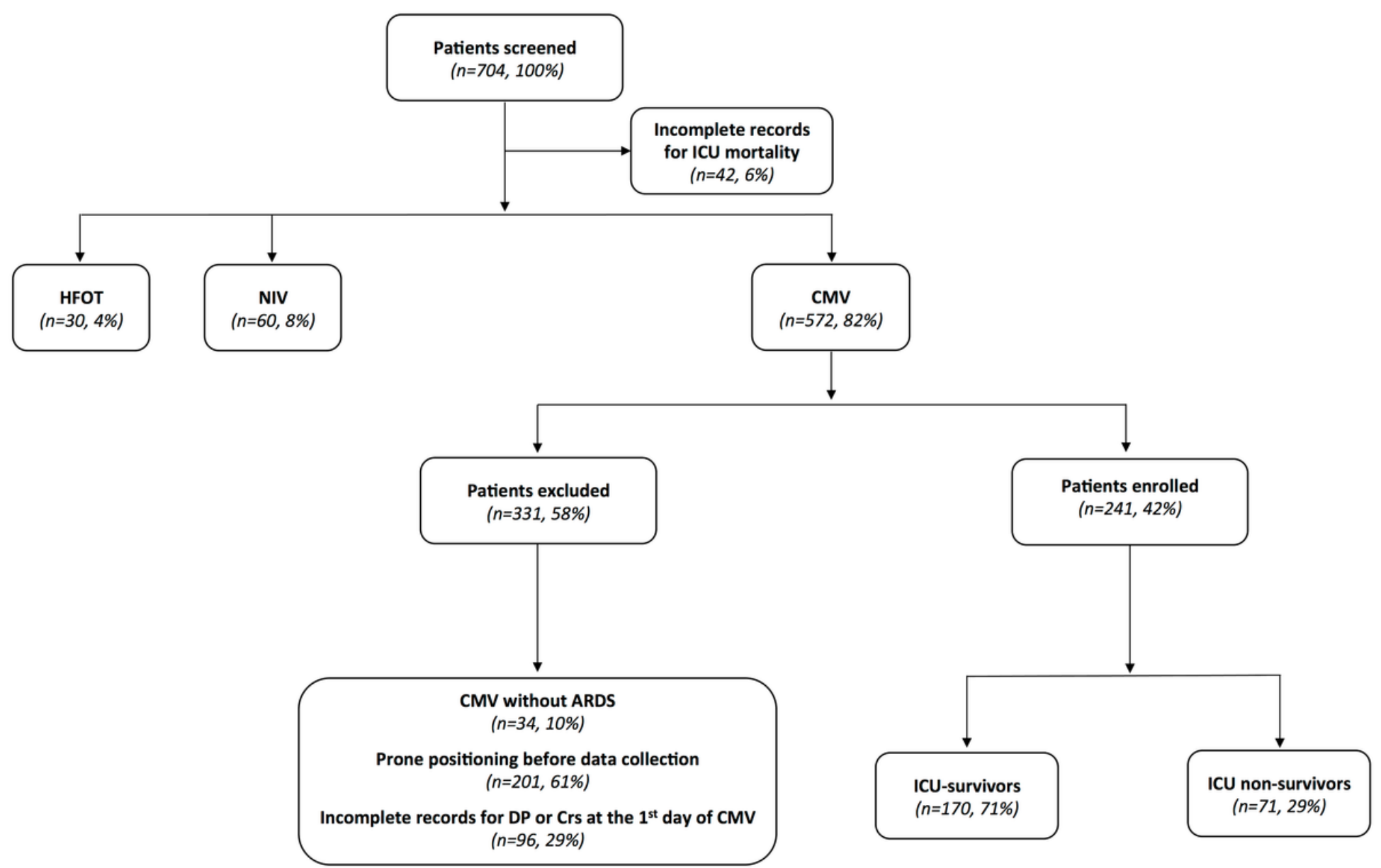

\section{Figure 1}

Flow chart of enrolled patients. Abbreviations: ICU, intensive care unit; HFOT, high flow oxygen therapy; NIV, non-invasive ventilation; CMV: controlled mechanical ventilation; ARDS: acute respiratory distress syndrome; DP, driving pressure; Crs, static compliance of the respiratory system. 


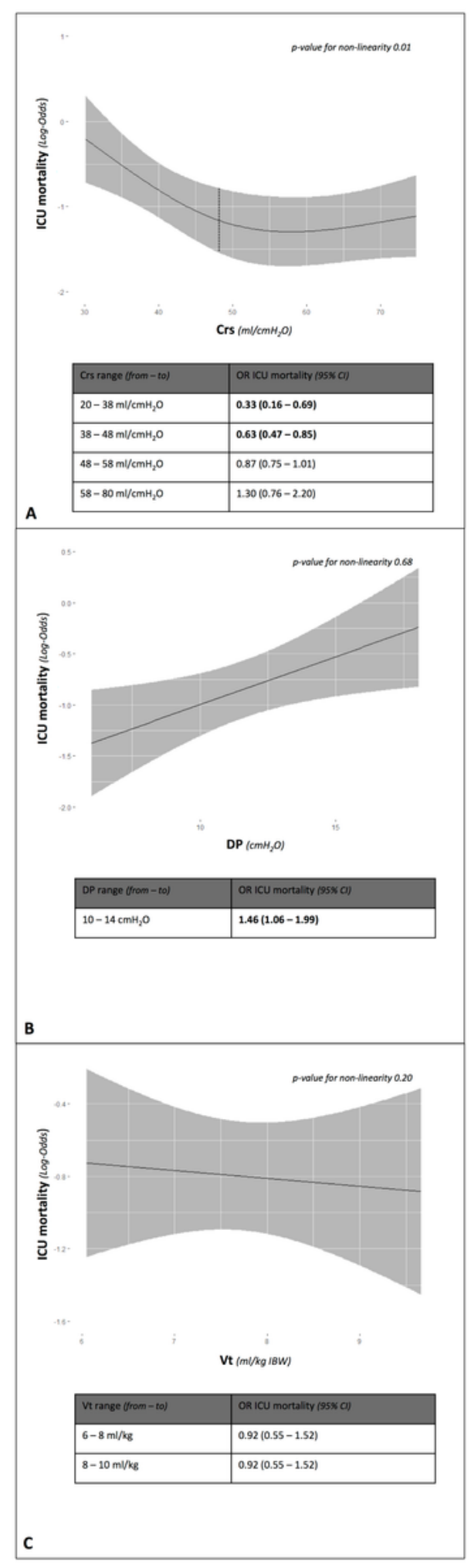

\section{Figure 2}

Solid lines indicate the log-odds of ICU mortality, while grey areas $95 \%$ confidence interval. A) Association between static compliance of the respiratory system and intensive care unit mortality. The p-value for non-linearity was 0.01 . The nonlinear effect of static compliance of the respiratory system on the intensive care unit mortality risk was modelled using restricted cubic splines. The odds ratio is presented for the interquartile ranges of the study population. B) Association between driving pressure and intensive 
care unit mortality. Because $p$-value for non-linearity was 0.68 , non-linearity was not implemented in the model. The odds ratio is presented for clinically relevant range of values, according to published data $[5,6]$. C) Association between tidal volume and intensive care unit mortality. Because p-value for nonlinearity was 0.20 , non-linearity was not implemented in the model. The odds ratio is presented for clinically relevant range of values, according to literature data [2,4]. Abbreviations: ICU, intensive care unit; Crs, static compliance of the respiratory system; DP, driving pressure; Vt, tidal volume; IBW, ideal body weight; OR, odds ratio; $95 \% \mathrm{Cl}, 95 \%$ confidence interval.

\section{Supplementary Files}

This is a list of supplementary files associated with this preprint. Click to download.

- AdditionalFile1.pdf 